gain from this polarization of $\mathrm{H}^{\prime}$ has been found to be about $1.5 \mathrm{kcal} / \mathrm{mole}$.

Summing up, the total computed energy gain from polarization effects is $0.2+\mathbf{1 . 5}=$ $1.7 \mathrm{kcal} / \mathrm{mole}$. This value is, however, not very definite. There are several factors, which could modify it in one direction or the other. One factor, which would increase it, is the fact that 0.2 and $1.5 \mathrm{kcal} / \mathrm{mole}$ should be considered as lower limits of the effects i) and ii). Another, which would diminish it, is the fact that the effect ii) should cause a slight weakening of the $\mathrm{O}^{\prime}-$ $\mathrm{H}^{\prime}$ bond. Although the value $1.7 \mathrm{kcal} / \mathrm{mole}$ is rather approximate, it is interesting to compare it with the purely electrostatic interaction energy. Using the point charge model, discussed by Bauer and Magat ", this energy is computed to $5.1 \mathrm{kcal} / \mathrm{mole}$. Thus, it is seen that the polarization energy is not a negligible part of the total $\mathrm{H}$ bond energy.

For comparison with $\mathrm{H}_{2} \mathrm{O}$ we have also studied the association of $\mathrm{H}_{2} \mathrm{~S}$, which has an electronic structure similar to that of $\mathrm{H}_{2} \mathrm{O}$. $\mathrm{H}_{2} \mathrm{~S}$ solidifies at $-82.9^{\circ} \mathrm{C}$, but it does not seem to have a definite crystalline form. We have studied the interaction of two $\mathrm{H}_{2} \mathrm{~S}$ molecules, $\mathrm{S}^{\prime}-\mathrm{H}^{\prime} \ldots . \mathrm{S}<_{\mathrm{H}}^{\mathrm{H}}$,assuming the atoms $\mathrm{S}^{\prime} \mathbf{H}^{\prime} \mathrm{S}$ to be on a straight line. In the case of $\mathrm{H}_{2} \mathrm{~S}$ we have only computed the above-mentioned polarization effect ii). We have found a small energy gain, about $0.05 \mathrm{kcal} / \mathrm{mole}$. Since the effect ii) is giving the main contribution to the polarization energy in the $\mathrm{H}_{2} \mathrm{O}$ case, it is reasonable to assume the total polarization energy in the association of $\mathrm{H}_{2} \mathrm{~S}$ to be of the order of magnitude of 0.05 $\mathrm{kcal} / \mathrm{mole}$. The purely electrostatic interaction energy is in this case computed to be $0.25 \mathrm{kcal} / \mathrm{mol} \Theta$, when a point charge model is used.

The numerical results of the present investigation are collected in Table 1.

Table 1. Effects contributing to $\mathrm{H}$ bond formation. Energies in $\mathrm{kcal} / \mathrm{mole}$.

\begin{tabular}{|c|c|c|c|c|c|}
\hline \multirow{2}{*}{ Molecule } & \multicolumn{2}{|c|}{ Polarization energy } & $\begin{array}{c}\text { Electro- } \\
\text { static } \\
\text { energy }\end{array}$ & $\begin{array}{c}\text { Exptl. } \\
\text { H bond } \\
\text { energy }\end{array}$ \\
\cline { 2 - 5 } $\mathrm{H}_{2} \mathrm{O}$ & 0.2 & 1.5 & 1.7 & 5.1 & 5.8 \\
$\mathrm{H}_{2} \mathrm{~S}$ & - & 0.05 & $\sim 0.05$ & 0.25 & - \\
\hline
\end{tabular}

From Table 1 it is seen that the polarization effects are important for the $\mathrm{H}$ bond formation in the $\mathrm{H}_{2} \mathrm{O}$ case, whereas they cannot have any influence in the $\mathrm{H}_{2} \mathrm{~S}$ case.

1. Bauer, E. and Magat, M. J. phys. radium [7] 9 (1938) 319.

2. Ehrenberg, L. and Fischer, I. Acta Chem. Scand. 2 (1948) 657.

3. Fischer, I. and Ehrenberg, L. Acta Chem. Scand. 2 (1948) 669.

4. Fischer, I. Arkiv Fysik 1 (1949) 495.

5. Bernal, J. D. and Fowler, R. J. Chem. Phys. 1 (1933) 515.

6. Ellison, F. O. and Shull, H. J. Chem. Phys. 21 (1953) 1420.

Received March 26, 1958.

\section{Some Advantages of Using a Mercury Cathode in the Kolbe Electro-synthesis NGUYEN DINH-NGUYEN}

Department of Medical Biochemistry, University of Gothenburg, Sweden

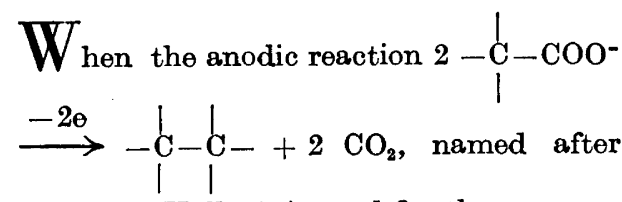
Hermann Kolbe ${ }^{1}$, is used for the preparation of alkali-sensitive substances such as esters, present practice usually avoids hydrolysis by electrolysing free carboxylic acids in the presence of only a few per cent of their sodium salts, the reaction being stopped when the electrolyte turns neutral. The solvent is generally methanol and the electrodes smooth platinum sheets.

In an attempt to prepare dimethyl adipate from methyl hydrogen succinate using this technique, a yield of only $38 \%$ was obtained, in contrast to the $70 \%$ reported by Bouveault ${ }^{2}$. He electrolysed equivalent amounts of succinic anhydride and sodium in methanol, using a watercooled platinum-tube anode and a mercury cathode. New runs were therefore made with mercury as cathode at the bottom of a beaker, and a platinum-sheet anode

Acta Chem. Scand. 12 (1958) No. 3 


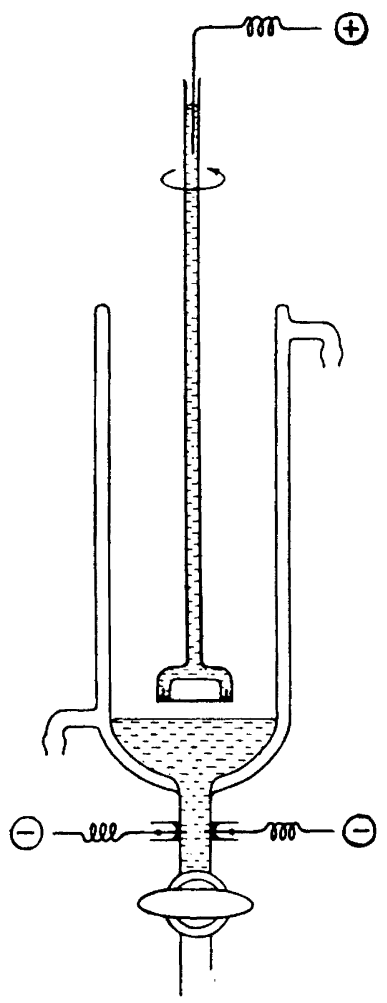

Fig. 1. Apparatus for Kolbe electro-synthesis with mercury as cathode.

was mounted horizontally $1 \mathrm{~cm}$ above the surface of the mercury. 50 to $100 \%$ of the half-ester in methanol was neutralized with sodium, and the beaker was cooled in running water as before. In this way the yield of dimethyl adipate rose to $55 \%$, and finally reached $68 \%$ when the anode was rotated at a speed high enough to bring about efficient stirring.

Apart from the improved yield in this particular case, the use of a mercury cathode has several other advantages. The mercury amalgamates the excess of discharged sodium ions, and the electrolyte does not turn alkaline as long as the voltage is applied. As much sodium as is practical may therefore be added, with the advan. tage of increased current density and consequently reduced reaction time. The current drops during the electrolysis, and the necessity of watching the $\mathrm{pH}$ is eliminated, as the ammeter indicates when the reaction should be interrupted. The electrolysis may probably be run for any length of time without harm, however, and is thus easily fitted into other work going on.

To facilitate separation of the electrolyte from the mercury without first stopping the electrolysis, the simple apparatus shown in Fig. 1 was devised. It is 8 beaker with double walls for water cooling, and with an outlet at the bottom. The outlet stem has a stopcock, and between this and the bottom of the beaker are two platinum threads melted through the stem wall, to connect the mercury with the negative pole. The platinum-sheet anode has short platinum threads melted into the stirrer tube, which is filled with mercury connected with the positive pole through the open upper end of the tube.

This work was made possible by grants from Statens naturvetenskapliga forskningsrad to S. Ställberg-Stenhagen. The hospitality of Hässle-Tika $A B$ is gratefully acknowledged.

1. For reviews on the Kolbe electro-synthesis see:

Knobel, M. and Brockman, C. J. Bibliography of Electro-organic Chemistry, National Research Council, Washington 1926; Swann, S. Jr. Bibliography of Electro-organic Chemistry. Part I, University of Illinois Engineering Experiment Station Circular Series No. 50, University of Illinois Bulletin 45 (1948) No. 69;

Weedon, B. C. L., Quart. Rev. London 4 (1952) 380;

Wladislaw, B. Selecta Chimica 14 (1955) 77; Swann, S. Jr. Electrolytic Reactions in Weissberger, A. Technique of Organic Chemistry, Interscience Publishers, New York and London 1956, vol. 2, p. 385.

2. Bouveault, L. Bull. soc. chim. France 29 (1903) 1038, 1043.

Received April 3, 1958. 